\title{
Capillary Characteristics and Applicability of Coal Bottom Ash as an Anti-Capillary Material for Coastal Constructions
}

\author{
Nguyen Ngoc Truc ${ }^{1, *}$, Nguyen Van Hoang ${ }^{1}$, Do Ngoc $\mathrm{Ha}^{2}$, Nguyen Thao $\mathrm{Ly}^{3}$ \\ ${ }^{1}$ VNU University of Science, 334 Nguyen Trai, Hanoi, Vietnam \\ ${ }^{2}$ Geotest JSC., Pham Hung, My Dinh 1, Hanoi, Vietnam \\ ${ }^{3}$ Agrarian and Technological Institute, The Peoples' Friendship University of Russia
}

Received 15 November 2019

Revised 17 February 2020; Accepted 26 February 2020

\begin{abstract}
Utilization of Coal bottom ash (CBA) as well as finding the solutions to prevent saline intrusion, meeting the needs of coastal infrastructure development have been considered by the authors of the article for a long time. In this study, the authors focused on analyzing capillary characteristics in order to find a suitable group of CBA particles, which can be applied in the design of foundations with the high ability in restricting or preventing the effects of salt in saline groundwater. The obtained results show that (1) The capillary height is inversely proportional to the particle size: the larger the particle, the smaller the capillary height and vice versa. The CBA group with a diameter of $2.0-5.0 \mathrm{~mm}$ has an average capillary height around $3.33 \mathrm{~cm}$; a group of particles size of $1.0-2.0 \mathrm{~mm}$ is $7.16 \mathrm{~cm}$; a group of particles size of $0.5-1.0 \mathrm{~mm}$ is $23.36 \mathrm{~cm}$. Meanwhile, the group of particles size of $0.1-0.5 \mathrm{~mm}$ is $31.26 \mathrm{~cm}$. (2) The capillary height is inversely proportional to the salt concentration in the capillary solution: the maximum capillary height exhibits with the lowest capillary solution salinity $\sim 0.0 \mathrm{~g} / \mathrm{L}$, whereas it reaches minimum value when salinity approximate $33.0 \mathrm{~g} / \mathrm{L}$. Thus, CBA with the same particle size of gravel (diameter from 2.0 to 5.0 $\mathrm{mm}$ ) is able to block capillary flow. This study forms the basis for the design solutions of anti-saline foundation, especially in the context of climate change and sea-level rise.
\end{abstract}

Keywords: Capillary, Coal Bottom Ash, Coal thermo electricity, Saline intrusion, Sea-level rise, Foundation.

\footnotetext{
* Corresponding author.

E-mail address: trucnn@vnu.edu.vn 


\title{
Đặc điểm mao dẫn và khả năng ứng dụng của xỉ đáy nhiệt điện than làm vật liệu chống mao dẫn muối cho công trình xây dựng ven biển
}

\author{
Nguyễn Ngọc Trực ${ }^{1, *}$, Nguyễn Văn Hoàng ${ }^{1}$, Đỗ Ngọc Hà2 ${ }^{2}$ Nguyễn Thảo Ly \\ ${ }^{1}$ Truờng Đại học Khoa học Tự nhiên, Đại học Quốc gia Hà Nội, 334 Nguyễn Trãi, Hà Nội, Việt Nam \\ ${ }^{2}$ Công ty cổ phần Geotest, Phạm Hùng, Mỹ Đình 1, Hà Nội, Việt Nam \\ ${ }^{3}$ Viện Khoa học Nông nghiệp, Đại học Hũu nghị các Dân tộc Liên Bang Nga
}

Nhận ngày 15 tháng 11 năm 2019

Chỉnh sửa ngày 17 tháng 02 năm 2020; Chấp nhận đăng ngày 26 tháng 02 năm 2020

\begin{abstract}
Tóm tắt: Việc nghiên cứu tận dụng phế thải công nghiệp cũng như tìm kiếm các giải pháp công trình chống nhiễm mặn, đáp ứng nhu cầu phát triển cơ sở hạ tầng ven biển được các tác giả quan tâm từ lâu. Trong bài báo này, các tác giả tập trung phân tích đặc điểm mao dẫn để tìm ra nhóm hạt xỉ đáy kích thước phù hợp, sử dụng trong thiết kế móng công trình có khả năng hạn chế, ngăn chặn ảnh hưởng của muối trong nước ngầm do xâm nhập mặn. Kết quả nghiên cứu cho thấy, (1) chiều cao mao dẫn tỉ lệ nghịch với kích thước hạt: hạt càng lớn, chiều cao mao dẫn càng nhỏ và ngược lại. Nhóm hạt xỉ đường kính từ 2,0-5,0 mm có chiều cao mao dẫn trung bình $3,33 \mathrm{~cm}$; nhóm hạt kích thước $1,0-2,0 \mathrm{~mm}$ là $7,16 \mathrm{~cm}$; nhóm hạt từ $0,5-1,0 \mathrm{~mm}$ là $23,36 \mathrm{~cm}$; nhóm hạt $0,1-0,5 \mathrm{~mm}$ là 31,26 $\mathrm{cm}$. (2) Chiều cao mao dẫn tỉ lệ nghịch với nồng độ muối trong dung dịch mao dẫn: chiều cao mao dẫn lớn nhất khi độ mặn dung dịch mao dẫn là $0,0 \mathrm{~g} / \mathrm{L}$; nhỏ nhất khi độ mặn dung dịch mao dẫn là $33,0 \mathrm{~g} / \mathrm{L}$. Như vậy, xỉ đáy với nhóm kích thước hạt tương đương sạn sỏi (từ 2,0-5,0 mm) có khả năng ngăn chặn dòng mao dẫn tốt nhất. Nghiên cứu này làm cơ sở cho các giải pháp thiết kế móng công trình chống mao dẫn muối liên quan đến xâm nhập mặn, nhất là trong bối cảnh biến đổi khí hậu và nước biển dâng hiện nay.
\end{abstract}

Tù khóa: Mao dẫn, xỉ đáy, nhiệt điện than, nhiễm mặn, nước biển dâng, công trình dân dụng.

\section{Mở đầu}

Nhiễm mặn là một loại hình thiên tai khá phổ biến ở các quốc gia ven biển, nhất là những vùng đất thấp ven biển. Trong bối cảnh biến đổi khi hậu và nước biển dâng, quá trình xâm nhập mặn diễn ra mạnh mẽ và ảnh hưởng không nhỏ đến đời sống, kinh tế, xã hội và cơ sở hạ tầng. Độ mặn của đất được xác định thông qua nồng độ muối trong dung dịch nước chiết xuất từ đất bão hòa. Theo đó, đất được coi là không nhiễm mặn

\footnotetext{
* Tác giả liên hệ.

Địa chỉ email: trucnn@vnu.edu.vn

https://doi.org/10.25073/2588-1094/vnuees.4517
}

nếu có nồng độ muối $\leq 3 \mathrm{~g} / \mathrm{L}$, khi nồng độ này $\geq$ $12 \mathrm{~g} / \mathrm{L}$ thì đất được coi là đất nhiễm mặn [1].

Ảnh hưởng của nhiễm mặn đã được các nhà khoa học nghiên cứu từ lâu, đáng kể tới như các tác giả M.N. Terletskaya; A.I. Grot; A.E. Oradovskaya; L.N. Lomize... đã nghiên cứu trên nhiều loại đất khác nhau [2-4]. V.P. Petrukhin từ những nghiên cứu lý thuyết và thực nghiệm trên các loại đất hoàng thổ có chứa thạch cao khu vực Trung Á, Kazakhstan, Ukraine... Ông đã đề cập đến biến dạng xói ngầm, đặc trưng độ bền của 
đất nhiễm mặn, những điểm cần quan tâm chú ý trong việc khảo sat địa kỹ thuật cũng như thiết kế móng cho công trình xây dựng trên đất nhiễm mặn thuộc các vùng đất nói trên $[3,5]$. Mặc dù vậy, một giải pháp chống nhiễm mặn hiệu quả cho công trình vẫn chưa được đưa ra trong các nghiên cứu này.

Ở trong nước, có nhiều tác giả tập trung nghiên cứu ở các lĩnh vực khác nhau, nhưng chủ yếu về các khía cạnh môi trường, sinh thái, nông nghiệp hoặc đánh giá hiện trạng, đặc điểm, diễn biến của xâm nhập mặn. Các nghiên cứu về tác động của nhiễm mặn đến cơ sở hạ tầng kỹ thuật, công trình ven biển chưa được quan tâm nhiều. Năm 1990, Phạm Văn Tỵ, Đỗ Minh Toàn cho rằng, tính chất đất sét trầm tích Đệ tứ khu vực ven biển thay đổi khá nhiều so với đất sét trong trầm tích Đệ tứ ở đồng bằng châu thổ, chủ yếu do khả năng chứa muối trong đất khác nhau [6]. Đến năm 2002, Tô văn Lận đã tập trung nghiên cứu sự biến đổi một số tính chất cơ lý của đất loại sét ven biển trong các điều kiện nhiễm mặn và tác động của muối đối với công trình ven biển [7]. Tuy nhiên, đây là những nghiên cứu bước đầu, làm cơ sở cho các nghiên cứu sau này.

Trong những năm gần đây, trước tình hình gia tăng xâm nhập mặn và các tác động tiêu cực của nhiễm mặn đến hệ thống cơ sở hạ tầng ven biển, đặc biệt là đường giao thông và công trình xây dựng dân dụng, Nguyễn Ngọc Trực và cộng sự đã có loạt công trình nghiên cứu về tác động của muối hòa tan đến nền đất và công trình. Các nghiên cứu điển hình phải kể đến như "Hanoi Cohesive Soil in Salt-Affected Conditions: Soil Properties and 2D Consolidation Analysis" [8], "Effect of saline intrusion on the properties of cohesive soils in the Red River delta, Vietnam" [9], "Soft soil in salt-affacted media: geotechnical perspectives" [10], "Bearing capacity analysis of Hanoi soft ground improved with reinforced foundation pad" [11], "Study of deformation of salt-affected soils by FEM, a case study of soft soil in the Red River delta, Vietnam" [12], "Một số đặc điểm địa kỹ thuật của đất yếu Hà Nội trong môi trường nhiễm mặn" [13], "Secondary consolidation of hanoi soft soil in saline saturated media related to climate change induced sealevel rise" [14].

Các tác giả đã đi sâu nghiên cứu, đánh giá sự biến đổi các tính chất của đất trong điều kiện nhiễm mặn, các đặc điểm biến dạng, lún sơ cấp và thứ cấp và phân tích sức chịu tải của nền đất nhiệm mặn. Để đánh giá rõ sự biến đổi cũng như mức độ biến đổi các tính chất của đất khi bị nhiễm mặn với nồng độ cao hơn, đồng thời đã bước đầu đặt vấn đề liên quan đến các tương tác hóa lý xảy ra bên trong cấu trúc của đất nhằm luận giải những biến đổi của các tính chất của đất trong môi trường mặn [1-4]. Mặc dù đã có những công trình nghiên cứu quan trọng, nhưng những ý tưởng nghiên cứu giải pháp thiết kế một loại móng công trình có khả năng phòng, chống, ngăn chặn quá trình mao dẫn muối liên quan đến nhiễm mặn vẫn chưa có.

Trong bối cảnh hoạt động công nghiệp phát triển mạnh mẽ ở Việt Nam hiện nay, nguồn phế thải công nghiệp như tro, xỉ đang trở nên dư thừa và gây nhiều hệ lụy về môi trường. Cả nước hiện có khoảng 21 nhà máy nhiệt điện đang hoạt động với tổng công suất 14,848 MW, tiêu thụ khoảng 45 triệu tấn than mỗi năm và thải ra hơn 16 triệu tấn tro xỉ (tro bay và xỉ đáy) mỗi năm. Ước tính đến năm 2025, sẽ có khoảng 47 nhà máy nhiệt điện có công suất khoảng $26,000 \mathrm{MW}$, các nhà máy này sẽ tiêu thụ khoảng 63 triệu tấn than mỗi năm và tổng lượng tro sẽ vượt quá 30 triệu tấn mỗi năm [15]. Trên thực tế, tổng lượng tro than tiêu thụ khoảng 20\% 30\% (chủ yếu là tro bay), trong khi xỉ đáy hầu như chưa được sử dụng và chủ yếu được lưu giữ trong các bãi thải của nhà máy.

Việc nghiên cứu tận dụng phế thải công nghiệp làm vật liệu chống mao dẫn muối liên quan đến nhiểm mặn được tác giả quan tâm từ lâu. Trong bài báo này, các tác giả đề cập đến khả năng ứng dụng của xỉ đáy nhiệt điện than làm vật liệu chống mao dẫn muối cho công trình dân dụng ven biển. Kết quả nghiên cứu làm cơ sở cho các giải pháp công trình chống nhiễm mặn nhằm đáp ứng nhu cầu phát triển cơ sở hạ tầng ven biển. 


\section{Phương pháp nghiên cứu}

\subsection{Chuẩn bị mẫu}

Để nghiên cứu đặc điểm mao dẫn của nước mặn trong môi trường xỉ đáy nhiệt điện than, tác giả đã chuẩn bị $25 \mathrm{~kg}$ mẫu được lấy tại bãi xỉ thải tại Phả Lại (Hình 1). Mẫu được rây, phân chia thành 4 nhóm cấp hạt tương đương với sạn $(5,0$ $-2,0 \mathrm{~mm})$, cát hạt thô $(2,0-1,0 \mathrm{~mm})$, cát hạt trung $(1,0-0,5 \mathrm{~mm})$, và cát hạt mịn $(0,5-0,1$ $\mathrm{mm})$. Dung dịch mao dẫn được sử dụng là nước biển nhân tạo có 7 nồng độ mặn khác nhau, bao gồm $0,0 \mathrm{~g} / \mathrm{L}, 4,95 \mathrm{~g} / \mathrm{l}, 9,9 \mathrm{~g} / \mathrm{L}, 14,75 \mathrm{~g} / \mathrm{l}, 19,8$ $\mathrm{g} / \mathrm{L}, 24,75 \mathrm{~g} / \mathrm{L}$ và $33,0 \mathrm{~g} / \mathrm{L}$. Đây là các nồng độ muối tương ứng với các mức nhiễm mặn 0,15 , $30,45,60,75$ và $100 \%$ độ mặn của nước biển nếu xem độ mặn trung bình của nước biển là 33,0 $\mathrm{g} / \mathrm{L}$. Việc sử dụng các nồng độ muối khác nhau trong môi trường xỉ đáy cấp hạt khác nhau nhằm xác định chiều cao mao dẫn của mỗi nhóm vật liệu, để từ đó tìm được cấp hạt tối ưu cho các giải pháp móng công trình chống nhiễm mặn của công trình xây dựng dân dụng ven biển.
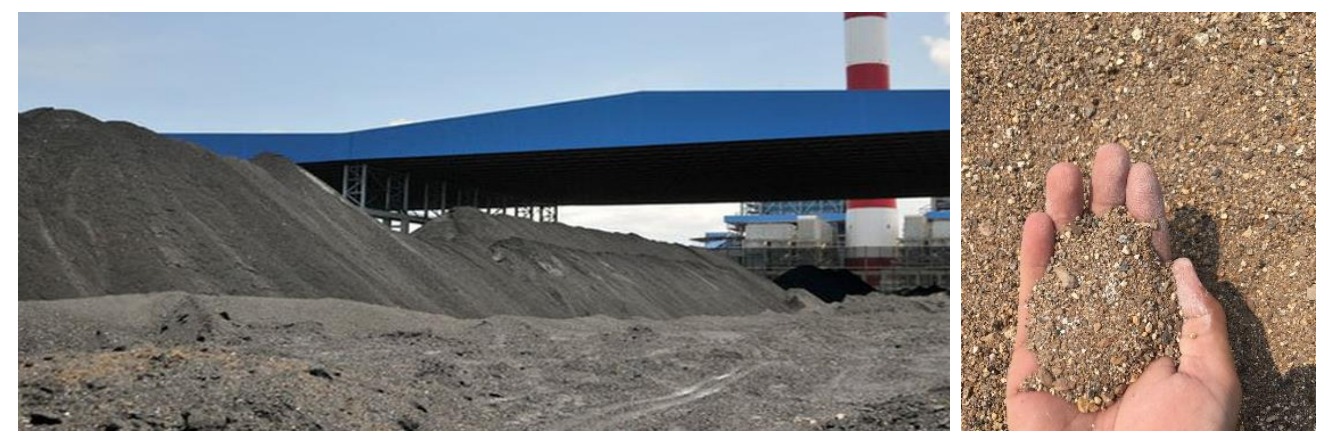

Hình 1. Xỉ đáy nhà máy nhiệt điện Phả lại 2, Hải Dương [16].

\subsection{Phưong pháp xác định khả năng mao dẫn của vật liệu (ASTM C1585 - 13)}

Mao dẫn là hiện tượng chất lỏng tự dâng lên cao trong vùng không gian hẹp mà không cần, thậm chí ngược hướng với ngoại lực. Nguyên nhân do bản thân trong chất lỏng có lực dính ướt. Khi lực dính ướt lớn hơn sức căng bề mặt thì dung dịch được kéo lên trên bề mặt chất lỏng một khoảng cách nhất định (Hình 2). Chiều cao mao dẫn phụ thuộc vào kích thước hạt, độ đồng nhất của vật liệu trong môi trường mao dần (tiết diện ống mao dẫn), và thành phần hóa học của dung dịch mao dẫn. Độ hút nước mao quản được đặc trưng bởi chiều cao mực nước dâng trong vật liệu $\left(h_{k}\right)$, được xác định bằng công thức $\left(^{*}\right)$ dưới đây và được mô tả trên Hình 3 :

$$
h_{k}=\frac{2 \delta \cos \theta}{r \gamma g}(*)
$$

Trong đó: $\delta$ là sức căng bề mặt; $\theta$ là góc thấm ướt; $g$ là gia tốc trọng trường; $r$ là bán kính ống mao quản; $\gamma$ là khối lượng riêng của nước.

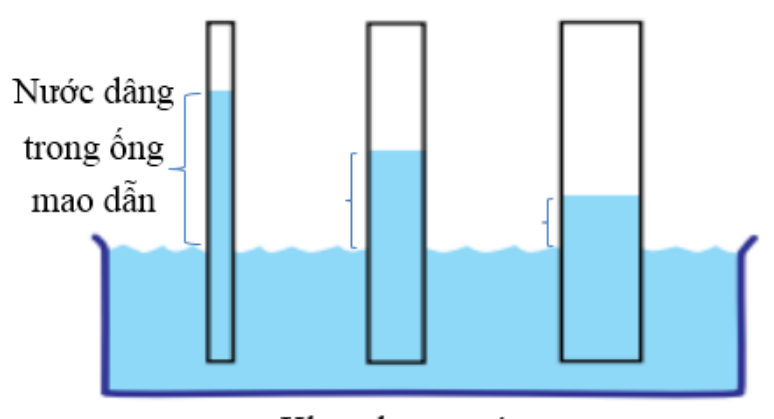

Khay đựng nước

Hình 2. Hiện tượng mao dẫn trong ống có tiết diện khác nhau. 


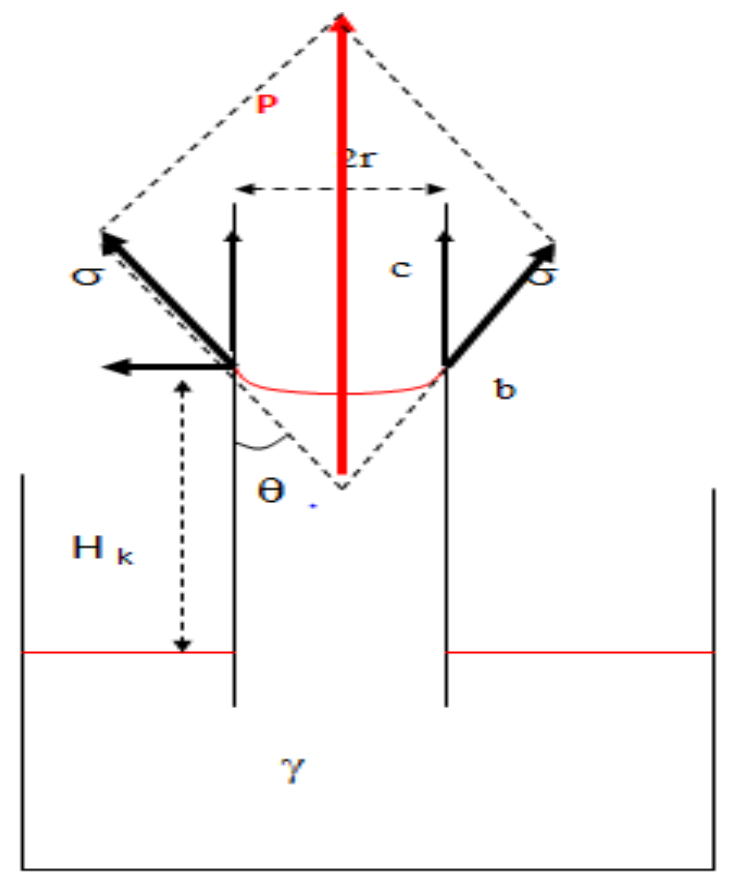

Hình 3. Mô tả công thức xác định độ mao dẫn.

Giá trị chiều cao mao dẫn tối đa theo thời gian của vật liệu rời tương ứng các cấp kích thước hạt tham khảo được cho trên Bảng 1:

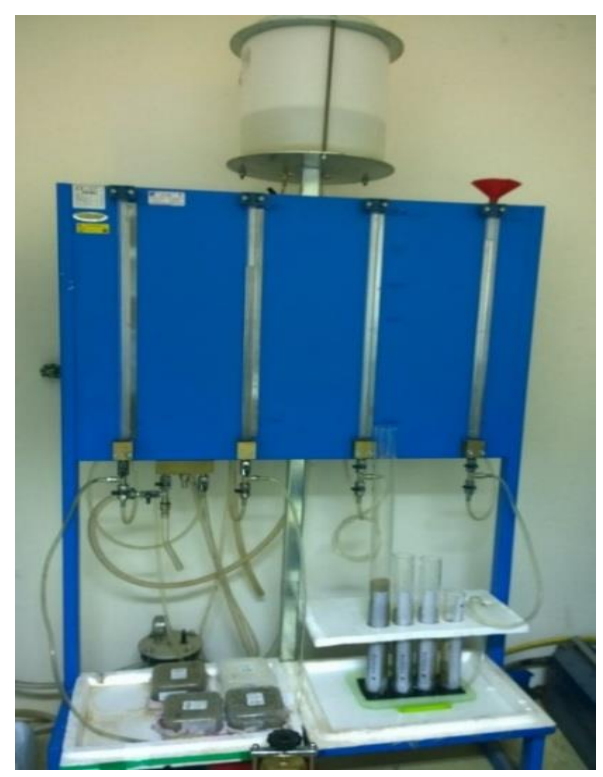

Bảng 1. Thời gian đạt đến giá trị cực đại của $h_{k}$ phụ thuộc vào kích thước hạt [17]

\begin{tabular}{|c|c|c|}
\hline $\begin{array}{c}\text { Kích thước hạt } \\
\text { vật liệu, } m m\end{array}$ & $\begin{array}{c}\text { Chiều cao mao } \\
\text { dẫn } H_{k}, \mathrm{~cm}\end{array}$ & $\begin{array}{c}\text { Thời gian, } \\
\text { ngày }\end{array}$ \\
\hline $5-2$ & 3,5 & 3 \\
\hline $2-1$ & 6,5 & 4 \\
\hline $1,0-0,5$ & 13 & 6 \\
\hline $0,5-0,1$ & 25 & 8 \\
\hline
\end{tabular}

Thí nghiệm xác định chiều cao mao dẫn được thực hiện với 4 cấp hạt đã được rây qua trong bước chuẩn bị mẫu thí nghiệm. Lấy bốn ống thủy tinh hở hai đầu có đường kính $4,8 \mathrm{~cm}$, bịt chặt một đầu ống thủy tinh bằng vải địa kỹ thuật không dệt sau đó đổ lượng cát cần thiết nhiều hơn chiều cao mao dẫn cực đại của các mẫu với thành phần hạt khác nhau.

Trên khay được lót một lớp vải địa kỹ thuật, dung dịch mao dần được đổ vào khay ngập ống thủy tinh 3,0 mm. Dung dịch mao dẫn được cung cấp vào khay thường xuyên để đảm bảo mực nước trong khay luôn ở mức 3,0 mm. Quá trình mao dẫn xảy ra ngay sau khi dung dịch mao dẫn xuất hiện trong khay. Có thể nhận thấy ngay mực nước thấm lên cao hơn mực nước ở khay, mỗi loại vật liệu khác nhau, ở các cấp hạt khác nhau, nồng độ muối trong dung dịch mao dẫn khác nhau sẽ có chiều cao mao dẫn khác nhau (Hình 4).

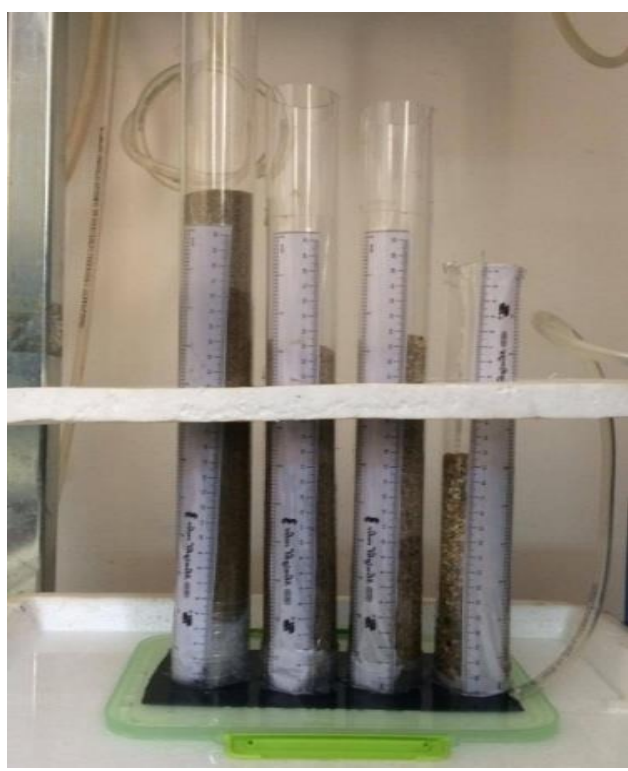

Hình 4. Thí nghiệm xác định khả năng mao dẫn của vật liệu. 
Ngay khi quá trình mao dẫn bắt đầu, quan sát và đo chiều cao mao dẫn liên tục theo thời gian. Đọc số đo cột nước theo thời gian lần lượt là 1 , $2,5,10,15,20,30,45,60,90,120,180,240$, $360, \ldots$ phút, đến khi số đọc giữa hai lần đọc gần nhau nhất không thay đổi thì dừng thí nghiệm (khoảng 2 - 3 ngày) [17].

Thiết lập mối quan hệ giữa thời gian mao dẫn $t(\min )$ và chiều cao mao dẫn $h_{k}(\mathrm{~cm})$. Từ đó phân tích, đánh giá mối quan hệ giữa nồng độ muối và chiều cao mao dẫn của vật liệu rời [17].

\section{Kết quả nghiên cứu}

\section{1. Đặc điểm của xỉ đáy nhiệt điện Phả Lại, Hải Duơng}

Trong nghiên cứu này, tác giả sử dụng xỉ đáy nhiệt điện than của nhà máy nhiệt điện Phả Lại, Hải Dương. Tro xỉ của các nhà máy nhiệt điện gồm các thành phần tạo ra từ quá trình phân hủy và biến đổi chất khoáng có trong than đá và các phụ gia. Các sản phẩm chính trong xỉ đáy nhiệt điện than theo công nghệ tầng sôi tuần hoàn (CFB) tại nhiệt điện Phả Lại gồm $85 \%$ tro bay và thạch cao, $15 \%$ xỉ đáy.

Xỉ đáy là những hạt vụn rời, là thành phần không cháy được, tập trung ở đáy lò. Thành phần phần hóa học chính của xỉ đáy là các oxit $\mathrm{SiO}_{2}$, $\mathrm{Al}_{2} \mathrm{O}_{3}, \mathrm{Fe}_{2} \mathrm{O}_{3}$ ngoài ra còn có $\mathrm{CaO}, \mathrm{MgO}, \mathrm{SO}_{3}$, $\mathrm{K}_{2} \mathrm{O}, \mathrm{Na}_{2} \mathrm{O}, \mathrm{TiO}_{2}, \mathrm{CaO}_{\mathrm{td}}, \mathrm{CaSO}_{4}$, ngoài ra còn có một lượng than chưa cháy hết $[16,18]$. Hàm lượng $\mathrm{SiO}_{2}$ và $\mathrm{Al}_{2} \mathrm{O}_{3}$ cao nên tro đáy cũng có khả năng hoạt động như một vật liệu pozzolanic. Mặt khác, sự có mặt của các thành phần $\mathrm{CaO}, \mathrm{SO}_{3}$, $\mathrm{CaSO}_{4}, \ldots$ sẽ thúc đẩy các quá trình hydrat hóa và sulphate liên quan đến $\mathrm{CaO}, \mathrm{CaSO}_{4}$ khi tiếp xúc với nước là điều kiện thuận lợi để cải thiện cường độ của tro đáy hoặc hồn hợp giữa tro đáy với các chất kết dính khác do sự hình thành các chất kết dính mới.

Kết quả phân tích mẫu cho thấy, khối lượng riêng của xỉ đáy tương đương với khối lượng riêng của đá dăm, sạn các loại. Thành phần hạt của xỉ đáy dùng cho nghiên cứu dao động từ cấp hạt tương đương hạt cát mịn $(0,125 \mathrm{~mm})$ đến hạt sạn $(20,0 \mathrm{~mm})$ và được thể hiện ở Hình 5 . Trên đồ thị thành phần hạt, nhóm hạt trung - thô chiếm chủ yếu (54.2\%), sau đó là nhóm hạt cuội sạn $(45,2 \%)$, nhóm hạt bột chiếm rất ít $0,64 \%$. Với những chỉ tiêu trên, tham khảo tiêu chuẩn TCN 304 - 03 nhận thấy xỉ đáy sử dụng cho nghiên cứu thuộc loại cấp phối $\mathrm{C}$, có khả năng làm chặt cao. Tuy nhiên, độ thoi dẹt của hạt xỉ cũng chiếm một hàm lượng đáng kể, khoảng $22,7 \%$, làm giảm chức năng làm chặt và cường độ của xỉ đáy.

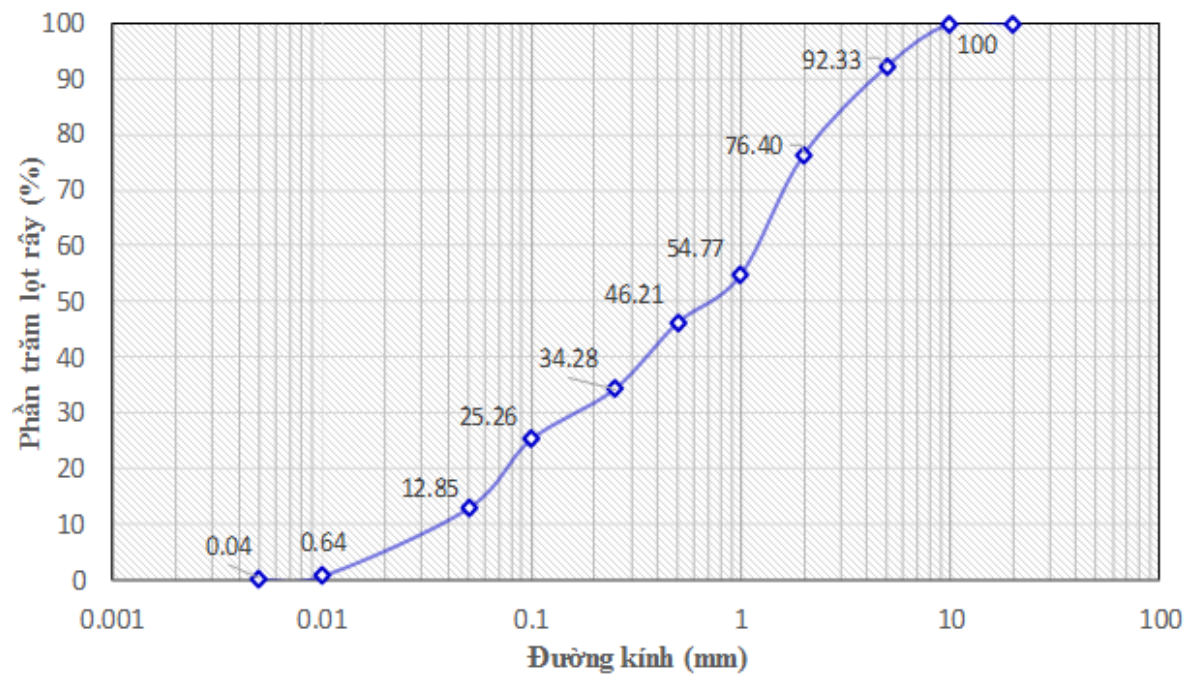

Hình 5. Thành phần hạt của xỉ đáy nhiệt điện Phả Lại. 
Thí nghiệm thấm được thực hiện theo tiêu chuẩn ASTM C1585-13 của Hiệp hội Thí nghiệm và Vật liệu Hoa Kỳ để đánh giá tính thấm của hỗn hợp vật liệu và từng nhóm cấp hạt trong xỉ đáy. Áp dụng phương pháp xác định hệ số thấm bằng phương pháp cột nước không đổi, đồng thời sử dụng định luật chảy tầng của Darcy để tính hệ số thấm của xỉ đáy tại mọi nhiệt độ xác định được đo trước khi làm thí nghiệm, hệ số thấm được xác định bởi công thức:

$$
\mathrm{K}_{\mathrm{th}}=0.01565 \frac{B . t}{\tau}
$$

Trong đó, $\mathrm{K}_{\text {th }}$ là hệ số thấm của đất ở nhiệt độ nước thí nghiệm, $\mathrm{cm} / \mathrm{s}$; $\mathrm{t}$ là thời gian thấm (giây); $\mathrm{B}$ là hệ số thiết bị, được xác định bởi công thức $\mathrm{B}=(-\ln (1-\mathrm{y} / \mathrm{H}))$; $\mathrm{y}$ là đường nước thấm, $\mathrm{y}$ $=10(\mathrm{~cm}) ; \mathrm{H}$ là chiều cao cột nước, $\mathrm{H}=30 \mathrm{~cm}$; $\tau$ là hệ số nhiệt được xác định bởi công thức $\tau=$ $0,7+0,03 . T ;$ T là nhiệt độ nước tại thời điểm thí nghiệm.

Các kết quả thí nghiệm được thể hiện trên bảng 2, qua đó có thể nhận thấy, hỗn hợp tro xỉ đáy lò nhiệt điện than có hệ số thấm trung bình là $1,04 \cdot 10^{-4} \mathrm{~cm} / \mathrm{s}$. Nhóm cấp hạt tương đương sạn sỏi có hệ số thấm lớn nhất, xấp xỉ $1,117.10^{-3}$; nhóm cấp hạt tương đương cát mịn có hệ số thấm nhỏ nhất, khoảng $1,866.10^{-5}$.

Bảng 2. Hệ số thấm của xỉ đáy nhiệt điện Phả Lại

\begin{tabular}{|c|c|}
\hline Cấp hạt vật liệu & $\begin{array}{c}\text { Hệ số thấm } \\
(\mathrm{cm} / \mathrm{s})\end{array}$ \\
\hline Hỗn hợp & $1,04.10^{-4}$ \\
\hline Sạn sỏi & $1,117.10^{-3}$ \\
\hline Hạt thô & $7,45.10^{-4}$ \\
\hline Hạt trung & $7,74.10^{-4}$ \\
\hline Hạt mịn & $1,866.10^{-5}$ \\
\hline
\end{tabular}

3.2. Đặc điểm mao dẫn của xỉ đáy nhiệt điện trong môi trường nhiếm mặn

Các thí nghiệm trong phòng tập trung xác định chiều cao mao dẫn ở các cấp hạt khác nhau. Sử dụng dung dịch mao dẫn có nồng độ muối hòa tan khác nhau nhằm đánh giá ảnh hưởng của độ mặn đến chiều cao mao dẫn. Các số liệu thí nghiệm được đo liên tục theo thời gian cho đến khi chiều cao mao dẫn đạt độ ổn định, tức là giá trị lần đọc sau không khác giá trị lần đọc trước. Hầu hết thời gian thí nghiệm đạt ổn định sau khoảng 2800 phút (khoảng 2 ngày). Thí nghiệm kết thúc sau tối đa 3500 phút.

Thí nghiệm xác định khả năng mao dẫn của xỉ đáy nhiệt điện than trong môi trường nhiễm mặn được tiến hành với 7 cấp nồng độ muối, gồm $0,0 \mathrm{~g} / 1 ; 4,95 \mathrm{~g} / \mathrm{l} ; 9,9 \mathrm{~g} / 1 ; 14,85 \mathrm{~g} / 1 ; 19,8 \mathrm{~g} / \mathrm{l}$; $24,75 \mathrm{~g} / 1$; và $33,0 \mathrm{~g} / \mathrm{l}$. Việc lựa chọn các cấp nồng độ muối dựa vào độ mặn trung bình của nước biển Việt Nam. Nếu xem nồng độ $0,0 \mathrm{~g} / \mathrm{l}$ tương ứng với $0 \%$ độ mặn nước biển thì $33,0 \mathrm{~g} / 1$ tương ứng với $100 \%$ độ mặn trung bình của nước biển. Các cấp nồng độ muối được lựa chọn ở trên là giá trị trung bình từ 0 đến $100 \%$. Giá trị chiều cao mao dẫn cho mỗi cấp kích thước hạt của vật liệu là giá trị số đọc cuối cùng, và cũng là giá trị lớn nhất trên đường cong. Bảng 3 tóm lược các giá trị chiều cao mao dẫn của các dung dịch trong các cấp hạt thí nghiệm của xỉ đáy.

Bảng 3. Chiều cao mao dẫn của dung dịch với nồng độ muối khác nhau trong xỉ đáy lò

\begin{tabular}{|c|c|c|c|c|c|c|c|}
\hline \multirow{2}{*}{ Cấp hạt } & \multicolumn{6}{|c|}{ Nồng độ dung dịch mao dẫn (g/L) } \\
\cline { 2 - 8 } & 0,0 & 4,95 & 9,9 & 14,85 & 19,8 & 24,75 & 33,0 \\
\hline Hạt mịn & 36,5 & 34,0 & 28,5 & 29,8 & 31,2 & 32,8 & 26,0 \\
\hline $\begin{array}{c}\text { Hạt } \\
\text { trung }\end{array}$ & 26,9 & 25,2 & 24,5 & 21,2 & 20,0 & 23,2 & 22,5 \\
\hline Hạt thô & 9,5 & 7,7 & 6,5 & 6,3 & 5,6 & 7,5 & 7,0 \\
\hline Sạn sỏi & 4,8 & 4,0 & 3,0 & 2,5 & 2,2 & 3,5 & 3,3 \\
\hline
\end{tabular}

Kết quả thí nghiệm là đường cong thể hiện mối quan hệ giữa chiều cao mao dẫn $(\mathrm{cm})$ theo thời gian (phút). Với tất cả 4 cấp hạt đều có thể xây dựng được phương trình quan hệ giữa chiều cao mao dẫn theo thời gian tương ứng với mỗi nồng độ muối. Ở giai đoạn đầu của thí nghiệm, sự gia tăng chiều cao mao dẫn diễn ra rất nhanh, phương trình quan hệ có dạng đường cong của hàm logarit $y=a \cdot \ln (x)+b$. Tiếp theo là giai đoạn ổn định với đường cong đi ngang, phương trình quan hệ có dạng hàm tuyến tính bậc nhất $y=a x$ $+b$, với $y$ là chiều cao mao dẫn, $x$ là thời gian. Hệ số tương quan $\mathrm{R}^{2}$ của các hàm này đều lớn hơn 0,85 (Hình 6). 

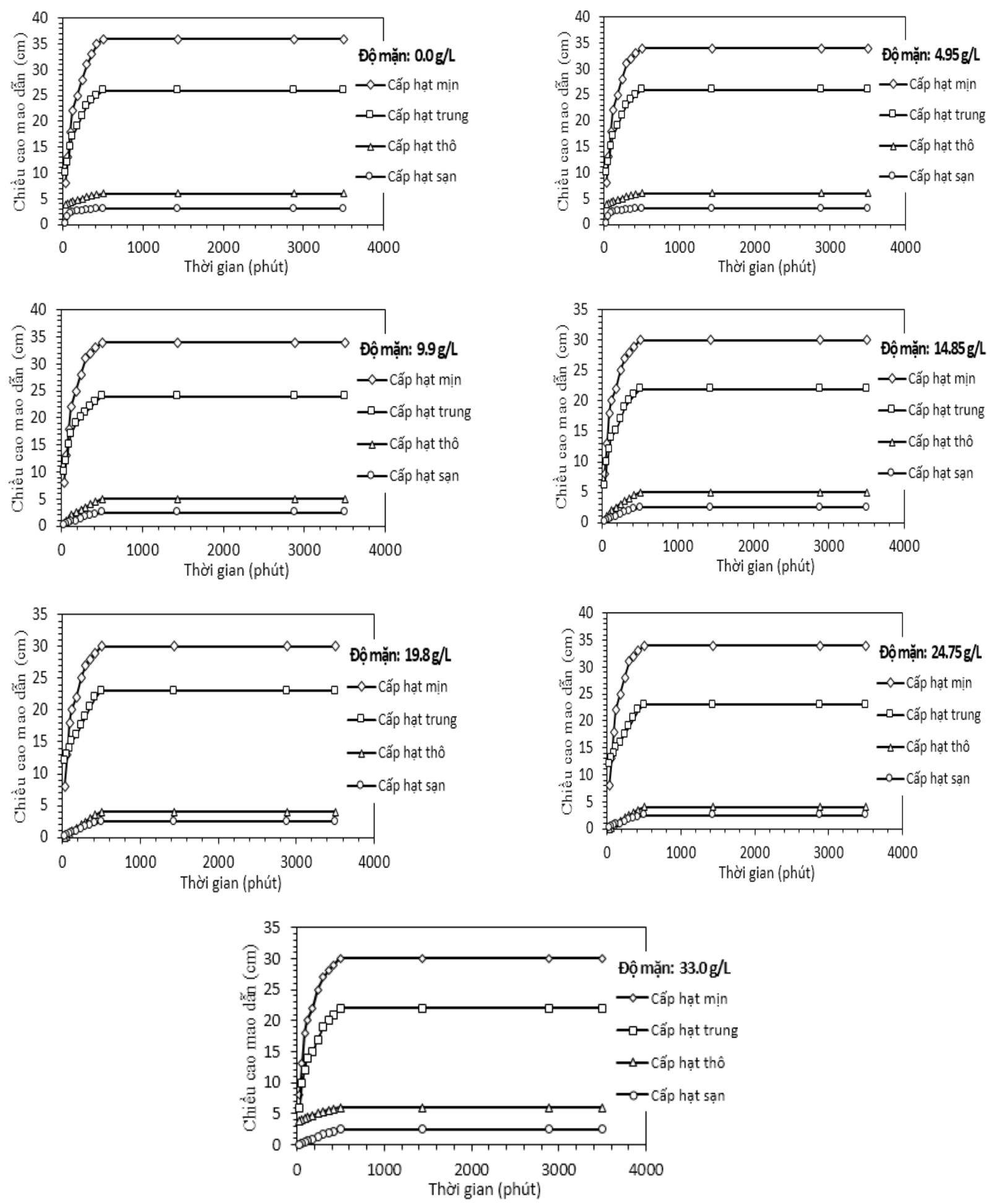

Hình 6. Chiều cao mao dẫn $\left(h_{k}\right)$ theo thời gian $(t)$ trong từng loại dung dịch mao dẫn của các nhóm xỉ đáy. 
Từ các đường cong $h_{k}-t$, có thể nhận thấy chiều cao mao dẫn quan hệ tỉ lệ nghịch với kích thước hạt của xỉ đáy. Kích thước hạt càng tăng thì khả năng mao dẫn càng giảm, cấp hạt tương đương cát mịn có chiều cao mao dẫn lớn nhất, cấp hạt tương đương sạn sỏi có chiều cao mao dẫn nhỏ nhất. Cụ thể, hạt cấp hạt sạn sỏi (5-2 $\mathrm{mm}$ ) có chiều cao mao dẫn trung bình $3,33 \mathrm{~cm}$; với cát hạt thô $(2-1 \mathrm{~mm})$ là $7,16 \mathrm{~cm}$; cát hạt trung (1-0,5 mm) là $23,36 \mathrm{~cm}$; cát hạt mịn $(0,5-0,1$ $\mathrm{mm}$ ) là $31,26 \mathrm{~cm}$.

Kết quả phân tích thu được cho thấy, diễn biến quá trình mao dẫn theo thời gian của dung dịch muối trong xỉ đáy có tính quy luật. Đánh giá một cách khái quát, chiều cao mao dần trong các cấp hạt xỉ đáy giảm khi bị nhiễm mặn. Tuy nhiên, diễn biến sự thay đổi chiều cao mao dẫn theo các nồng độ muối khá phức tạp. Hình 7 thể hiện mối quan hệ chiều cao mao dẫn $\left(\mathrm{h}_{\mathrm{k}}\right)$ theo nồng độ muối của các nhóm kích thước hạt, trong đó, đường đứt đoạn màu đỏ là đường trung bình diễn biến chiều cao mao dẫn. Với cấp hạt tương đương cát hạt trung, cát hạt thô và sạn, chiều cao mao dẫn giảm dần khi nồng độ muối tăng lên từ 0,$0 ; 4,95 ; 9,9 ; 14,85$ đến $19,8 \mathrm{~g} / \mathrm{L}$. Sau đó, từ độ mặn $19,8 \mathrm{~g} / \mathrm{L}$ đến $24,75 \mathrm{~g} / \mathrm{L}$, chiều cao mao dẫn tăng nhẹ lên cao hơn giá trị $h_{k}$ ở các độ mặn trước, nhưng vẫn thấp hơn $h_{k}$ trường hợp dung dịch mao dẫn $0,0 \mathrm{~g} / \mathrm{L}$. Khi nồng độ muối cao hơn $24,75 \mathrm{~g} / \mathrm{L}$ và tăng đến $33,0 \mathrm{~g} / \mathrm{L}$, chiều cao mao dẫn giảm dần với mức giảm khá lớn.

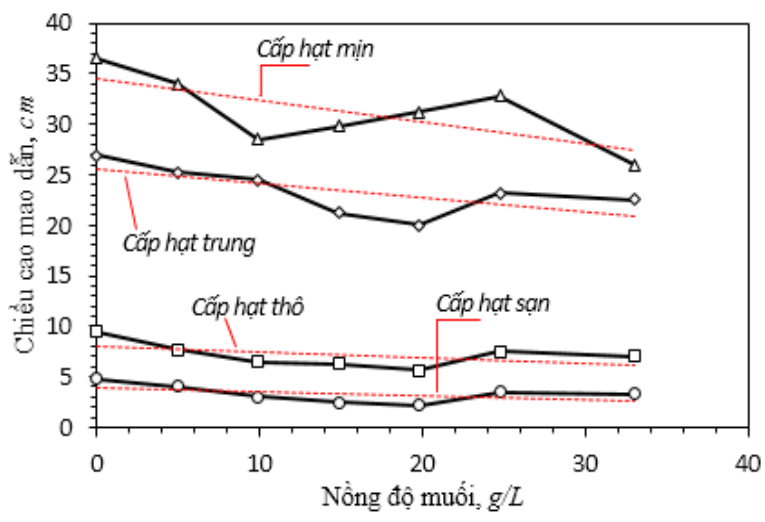

Hình 7. Chiều cao mao dẫn $\left(h_{k}\right)$ theo nồng độ muối của các nhóm kích thước hạt xỉ đáy.
Với nhóm vật liệu cấp hạt mịn, sự giảm chiều cao mao dẫn khi nhiễm mặn chỉ diễn ra khi dung dịch mao dẫn có độ mặn từ 0,0 đến $9,9 \mathrm{~g} / \mathrm{L}$. Khi độ mặn mặn vượt quá $9,9 \mathrm{~g} / \mathrm{L}$ lên đến $24,75 \mathrm{~g} / \mathrm{L}$, chiều cao mao dẫn $h_{k}$ tăng dần đáng kể. Sau độ mặn $24,75 \mathrm{~g} / \mathrm{L}$, chiều cao mao dẫn lại giảm mạnh, thấp hơn chiều cao mao dẫn tại $0,0 \mathrm{~g} / \mathrm{L}$.

Như vậy có thể nhận thấy, chiều cao mao dẫn $h_{k}$ trong xỉ đáy đạt giá trị cao nhất khi dung dịch bão hòa chưa bị nhiễm mặn, hay nồng độ muối là $0,0 \mathrm{~g} / \mathrm{L}$; và $h_{k}$ hầu như nhỏ nhất khi dung dịch bão hòa đạt đến độ mặn nghiên cứu, tương đương nước biển tự nhiên $(33,0 \mathrm{~g} / \mathrm{L})$. Ở khía cạnh kích thước hạt, $h_{k}$ tỉ lệ nghịch với đường kính mao dẫn, hay đường kính hạt. Chiều cao mao dẫn lớn nhất khi môi trường bão hòa có cấp hạt tương đương cát hạt mịn, và nhỏ nhất trong môi trường bão hòa có cấp hạt tương đương sạn sỏi.

\section{Thảo luận}

Chiều cao mao dẫn được tính toán lý theo các nguyên lý vật lý thông thường. Chiều cao đó phụ thuộc vào độ đồng nhất của môi trường mao dẫn, hình dạng và kích thước hạt vật liệu trong môi trường (tức là góc thấm ướt, và bán kính mao quản), thành phần hóa học và nồng độ dung dịch mao dẫn (tức là sức căng bề mặt và khối lượng riêng của dung dịch). Do đó, kết quả thí nghiệm thu được có sự phân dị khá rõ ràng giữa các mẫu vật liệu, các cấp hạt, và nồng độ muối của dung dịch.

Trong môi trường nhiễm mặn, chiều cao mao dẫn của dung dịch nhỏ hơn khi chưa nhiễm mặn là do nồng độ muối trong dung dịch càng tăng thì khối lượng riêng $\gamma$ của nước càng cao. Đồng thời, khi nồng độ muối tăng dẫn đến sức căng bề mặt dung dịch $\delta$ giảm xuống, điều này dẫn đến góc thấm ướt $\theta$ của dung dịch tăng lên, khi đó giá trị $\cos \theta$ trong công thức $(*)$ giảm xuống. Bên cạnh đó, chiều cao mao dẫn $h_{k}$ còn phụ thuộc vào thành phần hóa học của dung dịch bão hòa. Ví dụ, dung dịch chứa muối ăn natri chlorua $\mathrm{NaCl}$ thường làm chiều cao mao dẫn thấp hơn dung dịch nước tinh khiết, trong khi dung dịch chứa 
kiềm $\mathrm{NaOH}$ làm chiều cao mao dẫn cao hơn cả dung dịch nước tinh khiết và natri chlorua $\mathrm{NaCl}$.

Trong nghiên cứu này, sự biến đổi chiều cao mao dẫn trong xỉ đáy từ các cấp hạt tương đương sạn sỏi, cát hạt thô, cát hạt trung và cát hạt mịn thể hiện rất rõ ràng, do kích thước hạt liên quan đến bán kính mao quản. Cấp hạt càng lớn, chiều cao mao dẫn càng nhỏ và ngược lại. Ảnh hưởng của nồng độ muối trong dung dịch lên chiều cao mao dẫn ở cùng một cấp kích thước hạt thể hiện khá phức tạp. Giai đoạn độ mặn nghiên cứu ở mức trung gian trung gian, tức là từ $19,8 \mathrm{~g} / \mathrm{L}$ đến $24,75 \mathrm{~g} / \mathrm{L}$, chiều cao mao dẫn tăng lên cao hơn chiều cao ở các độ mặn trước liên trước. Mặc dù sự gia tăng chiều cao mao dẫn khi độ mặn tăng lên chỉ xảy ra với giá trị vừa phải, chưa vượt quá chiều cao ban đầu nhưng đây là điều khá bất thường. Cần có thêm số lượng các thí nghiệm để khẳng định và giải thích điều này. Đường xu thế hay đường giá trị trung bình của chiều cao mao dẫn theo nồng độ muối của các nhóm kích thước hạt xỉ đáy vẫn giảm dần khi nồng độ muối tăng lên.

Xỉ đáy nhiệt điện than đã được quan tâm nghiên cứu và ứng dụng nhiều trên thế giới. Chúng được đề xuất sử dụng làm vật liệu xây dựng, san lấp và phụ gia. Mặc dù vậy, hầu như chưa có các ý tưởng nghiên cứu ứng dụng xỉ đáy làm vật liệu chống mao dẫn muối liên quan đến nhiễm mặn cho công trình xây dựng dân dụng, đặc biệt trong bối cảnh biến đổi khí hậu và nước biển dâng. Vì thế, nghiên cứu này sẽ là cơ sở cho các giải pháp thiết kế móng, công trình chống mao dẫn muối liên quan đến xâm nhập mặn. Cụ thể, trong thiết kế móng công trình, có thể dựa vào tương quan giữa chiều cao mao dẫn với kích thước hạt để bố trí một lớp đá sạn dăm dưới nền và trên mực nước ngầm để ngăn chặn dòng mao dẫn, từ đó sẽ giảm được sự lan truyền muối trong thân công trình.

\section{Kết luận}

Trong bối cảnh biến đổi khí hậu và nước biển dâng, tai biến nhiễm mặn diễn ra ngày càng nghiêm trọng, ảnh hưởng đến các họat động kinh tế - công trình ven biển. Trong bài báo này, các tác giả đề cập đến khả năng ứng dụng của xỉ đáy nhiệt điện than làm vật liệu chống mao dẫn muối cho công trình dân dụng ven biển. Nguồn xỉ đáy được lấy từ nhà máy nhiệt điện Phả Lại, Hải Dương. Chúng được rây để phân chia thành các nhóm cấp hạt tương đương sạn sỏi, cát thô, cát vừa, cát mịn. Dung dịch dùng cho thí nghiệm mao dẫn là nước biển nhân tạo có các nồng độ muối 0,$0 ; 4,75 ; 9,9 ; 14,85 ; 19,8,24,75$; và 33,0 $\mathrm{g} / \mathrm{L}$. Thí nghiệm được thực hiện nhằm xác định chiều cao mao dẫn theo thời gian của các nhóm hạt xỉ trong các môi trường nhiễm mặn khác nhau.

Kết quả nghiên cứu đã xác định được nhóm kích thước hạt có khả năng ngăn chặn dòng mao dẫn, chống nhiễm mặn và lan truyền muối trong thân công trình. Cụ thể:

- Chiều cao mao dẫn tỉ lệ nghịch với kích thước hạt. Hạt càng lớn, chiều cao mao dẫn càng nhỏ và ngược lại. Nhóm hạt xỉ kích thước tương đương sạn sỏi $(5-2 \mathrm{~mm})$ có chiều cao mao dẫn trung bình $3,33 \mathrm{~cm}$; với cát hạt thô $(2-1 \mathrm{~mm})$ là $7,16 \mathrm{~cm}$; cát hạt trung $(1-0,5 \mathrm{~mm})$ là $23,36 \mathrm{~cm}$; cát hạt mịn $(0,5-0,1 \mathrm{~mm})$ là $31,26 \mathrm{~cm}$.

- Chiều cao mao dẫn tỉ lệ nghịch với nồng độ muối trong dung dịch mao dẫn. Chiều cao mao dẫn lớn nhất khi độ mặn dung dịch mao dẫn là $0,0 \mathrm{~g} / \mathrm{L}$; nhỏ nhất khi độ mặn dung dịch mao dẫn là $33,0 \mathrm{~g} / \mathrm{L}$. Sự phụ thuộc của chiều cao mao dẫn vào nồng độ muối không quá lớn trong nhóm hạt tương đương sạn sỏi và hạt thô, do đó có thể xem xét sử dụng các nhóm hạt này làm vật liệu chống mao dẫn muối cho công trình dân dụng ven biển.

\section{Lời cảm ơn}

Bài báo được hoàn thành với sự hỗ trợ của đề tài cấp Đại học Quốc gia Hà Nội, Mã số: QG. 18.15 "Nghiên cứu ảnh hưởng và đề xuất các giải pháp kỹ thuật giảm thiểu tác động của xâm nhập mặn đến ổn định nền-móng công trình xây dựng dân dụng trên nền đất yếu ven biển thành phố Hải Phòng". 


\section{Tài liệu tham khảo}

[1] N.N. Truc, A.L. Mihova."Soft soil in salt-affected media”, Vietnam National University Press 9/2015.

[2] A.L. Mihova, N.N. Truc "Bearing capacity analysis of hanoi soft ground improved with a reinforced foundation pad".

[3] A.L. Mihova, N.N. Truc, "Constitutive models for settlement analysis of soft salt-affected ground", 14th International Scientific Conference VSU'2014, 9/2014.

[4] ASTM International, (2014), Active Standard ASTM C1585-13.

[5] V.P. Petrukhin, "Construction of structures on saline soils", A.A. Balkema/Rotterdam.Brookfield, 1993.

[6] D.M. Toan, "Formation of the geological characteristics of Holocene sedimentary formations on the Marine - swamp origin in the Northern and the ability to use them for construction purposes", Candidate of Sciences thesis in Geography - Geology, Ha Noi University of Mining and Geology, 1993. (in Vietnamese).

[7] T.V. Lan, "Utilization on the effect of saline environment and salinization on the stability and deformation of construction works' foundation", $\mathrm{PhD}$ thesis in Engineering, The Southern Institute of Water Resources Research, Ho Chi Minh city, 2002. (in Vietnamese).

[8] N.N. Truc, L. Mihova, Hanoi Cohesive Soil in Salt-Affected Conditions: Soil Properties and 2D Consolidation Analysis. International Journal of Civil Engineering, https://doi.rog/10.1007/s40999 -019-00422-5, 2019.

[9] N.N. Truc, L. Mihova, T. Mukunoki, D.M. Duc, Effect of Saline Intrusion on the Properties of
Cohesive Soils in the Red River Delta, Vietnam, Marine Georesources \& Geotechnology, 2019.

[10] N.N. Truc, L.A. Mihova, Soft soil in salt - affected media: geotechnical perspectives. VNU Press, Hanoi, 282p, 2015.

[11] L.A. Mihova, N.N. Truc, Bearing capacity analysis of Hanoi soft ground improved with reinforced foundation pad, Engineering Science, Year LIII, Scientific journal of the Bulgarian Academy of Sciences, 2016.

[12] L.A. Mihova, N.N. Truc, 2015. Study of deformation of salt-affected soils by FEM, a case study of soft soil in the Red River delta, Vietnam. ECSMGE 17 (12) (2015) 4013-4018. ICE Publishing, https://doi.rog/10.1680/ecsmge.60678.vol7.634.

[13] N.N. Truc, "Some geotechnical characteristics of Hanoi soft soil in saline environment", VNU Journal of science, Natural science and technology 30 (2S) (2014) 12-20. (in Vietnamese).

[14] N.N. Truc, B. Kirov, Secondary consolidation of hanoi soft soil in saline saturated media related to climate change induced sealevel rise, 2013.

[15] Vietnamese Government, The Approval of Revisions to the National Power Development Plan from 2011 to 2020 with Visions Extended to 2030, Vietnamese Government, Hanoi, Vietnam, 2016.

[16] L.N. Hai, N. K, "Fly ash and applications", Ha Noi: Economic and Technology Information CNHC Vol 06-2014. (in Vietnamese).

[17] ASTM International, (2014), Active Standard ASTM C1585-13.

[18] Vietnam Standards TCVN 4315:2007 in Granulated blast furnace slag for cement production. (in Vietnamese). 